\title{
ASSOCIATION BETWEEN PERIODONTITIS AND GESTATIONAL DIABETES MELLITUS
}

\author{
Muhammad Sharjeel, Khurram Ataullah, Zubair Ahmed Khan, Myra Ahmed \\ Fatima Memorial Hospital, Lahore Pakistan
}

\begin{abstract}
Objective: To evaluate association between periodontal disease and gestational diabetes mellitus.

Study Design: Case control study.

Place and Duration of Study: This study was carried out at Department of Periodontology, Fatima Memorial Hospital, Lahore, from Jul 2016 to Jan 2017.

Methodology: A total of 140 patients divided into 2 groups i.e., cases \& controls (70 in each group) were included the study. Periodontal examination was carried out by a WHO periodontal probe and clinical measurements of periodontal conditions including Bleeding on Probing (BOP), Probing Depth (PD) and Clinical Attachment Level (CAL) were recorded. A single periodontology resident took all the said measurements.

Results: Patients ranged between 20-45 years of age. Mean age of the patients was $31.37 \pm 5.07$ years and $31.57 \pm$ 4.27 years in cases and controls, respectively. In cases periodontitis was found in 52 patients (74.3\%) while 37 patients $(52.9 \%)$ were having periodontitis in control group. There was an association between periodontal disease and gestational diabetes mellitus (GDM) (odds ratio 2.58).

Conclusion: In conclusion, periodontitis in pregnancyis found to increase the risk for gestational diabetes mellitus compared to women without periodontitis.
\end{abstract}

Keywords: Association, Gestational diabetes, Periodontal disease.

This is an Open Access article distributed under the terms of the Creative Commons Attribution License (http://creativecommons.org/licenses/by/4.0), which permits unrestricted use, distribution, and reproduction in any medium, provided the original work is properly cited.

\section{INTRODUCTION}

Periodontitis in humans is the most common chronic disease which is defined as inflammation of the gingiva encompassing the adjacent attachment apparatus leading to loss of clinical attachment due to destruction of periodontal ligament and its supporting bone ${ }^{1}$. The reported prevalence varies between $10 \%$ in adults ${ }^{2}$. Tobacco smoking, diabetes, pathogenic bacteria and microbial tooth deposits arereported risk factors for periodontal disease ${ }^{2}$.

Diabetes mellitus (DM) is a chronic disease associated with abnormally high blood sugar levels ${ }^{3}$. In a global review of 2018, 451 million people have diabetes and it is expected to increase to 693 million by 20453 with type 2 diabetes making up about $90 \%$ of the cases. Untreated diabetes mellitus is strongly linked with periodontal disease and is considered its sixth complication 4 . There is a higher estimated risk of periodontal

Correspondence: Dr Muhammad Sharjeel, Department of Periodontology, Fatima Memorial Hospital, Lahore Pakistan Received: 30 Jun 2019; revised received: 13 Jan 2020; accepted: 16 Jan 2020 disease during pregnancy. Gingival tissues can be accessed by lipopolysaccharide (LPS), endotoxins and other bacterial constituents and can start local inflammatory reactions, and further increase the levels of pro inflammatory cytokines 5,6 .

The type of DM first diagnosed in pregnancy is called gestational diabetes mellitus (GDM) ${ }^{7}$. The incidence of GDM lies between $2 \%$ to $14 \%$ in the world and is rising 8 . Its prevalence ranges between 20 to $50 \%$. Increased maternal age, previous GDM, obesity, polycystic ovarian syndrome, stillbirth, macrosomia and family history of diabetes mellitus (DM) are risk factors for GDM99. Literature suggests a correlation between GDM and inflammation by increased levels of C-reactive protein $(\mathrm{CRP})$ and inflammatory mediators like tumor necrosis factor- $\alpha(\alpha)$ and inter leukin-6 $\left(\right.$ IL-6) ${ }^{10}$. These makers in turn impede insulin functioning at cellular level and also act as insulin competitors. Hence, persistent increased levels of IL- 6 and TNF- $\alpha$ can hinder carbohydrate metabolism and therefore cause glucose intolerance. Amplified levels of inflammatory mediators is 
linked with periodontitis and thus maybe a risk factor for GDM ${ }^{11,12}$.

Periodontitis was diagnosed in $77.4 \%$ of females with GDM and in $57.5 \%$ in women without GDM in a case control study2. Some studies have shown periodontitis as a risk factor for GDM, while others have shown it to be a risk factor for adverse pregnancy outcomes such as preterm birth and low birth weight ${ }^{2}$. Studies do not give a clear picture whether periodontitis is a risk factor for GDM as certain studies clearly show it a risk factor and some studies do not prove this hypothesis.

The aim of this study was to determine the association between periodontal disease and gestational diabetes mellitus. This study was conducted to confirm the findings of the existing studies in our population in order to form a definite literature basis.

\section{METHODOLOGY}

The study design was case control study and the study was carried out at department of Periodontology, Fatima Memorial Hospital, Lahore. It is a tertiary care hospital affiliated to University of Health Science, Lahore.

This study was conducted in six months from 26-07-2016 to 25-01-2017. This subjects were divided into two equal groups visa avis cases \& controls. A total of 140 cases as sample size (70 in each group) was calculated. The power of test was $80 \%$ and level of significance was $5 \%$. Expected percentage of gestational diabetes mellitus in case and control groups was $77.4 \%$ in cases and $57.5 \%$ in control group-2. Non-probability consecutive was the sampling technique.

All pregnant female patients with chronological age starting from 18 to 45 years with gestational age from 24 to 30 weeks since last menstrual period having $>12$ permanent teeth in mouth were included in study. Women having abnormal glucose levels (when fasting and at 1, 2, and 3 hours) on OGTT was diagnosed as having Gestational Diabetes Mellitus and were defined as cases. Controls were defined as women whose
OGTT was negative at 24 to 30 weeks and were not diagnosed of other types of DM.

Patients diagnosed with pre gestational type I and type II DM were not included in study. Patients who were on insulin or any other oral hypoglycemic drugs before the pregnancy were also excluded. Patients in whom probing was contraindicated during examination of oral cavity were those with heart disorders, who underwent periodontal treatment during the past 3 months, patients receiving radiotherapy for head and neck region, smokers and alcohol users.

All patients who fell intosample selection criteria and came to the outdoor and indoor department of Fatima Memorial Hospital Medical and Dental College Lahore were chosen. Informed verbal consent was taken. Patient's name, age, sex, address, hospital registration number was noted. Periodontal examination was carried out by a WHO periodontal probe. Clinical measurements of periodontal conditions including Bleeding On Probing (BOP), Probing Depth (PD) and Clinical Attachment Level (CAL) were recorded. BOP was checked by probing to the base of the sulcus and represented as the percentage of bleeding sites over the total tooth surfaces. Probing Depth was recorded as the distance measured millimeters from the margin of gingiva to the pocket base. Clinical attachment level was calculated by adding the dimensions of recession and PD measurements. A single periodontology resident took all the said measurements.

Data was entered and analyzed in computer program Statistical Package for Social Sciences (SPSS) version 17. Mean and standard deviation was calculated for quantitative variables like age, frequency, percentage also calculated for qualitative variables like gestational diabetes mellitus (GDM) among both groups. $p$-value was calculated by applying chi-square test. Value of $<0.05$ was considered as statistically significant. Odds ratio (OR) was evaluated to determine the relationship between periodontitis and GDM by applying binary logistic regression. OR $>1$ was considered as statistically significant. Data was 
stratified for age to address the effect modifier and groups were created from previously published article ${ }^{2}$. Post-stratification adjusted OR was calculated. OR $>1$ was considered significant.

\section{RESULTS}

Patients ranged between 20-45 years of age. Average age of the patients was $31.37 \pm 5.07$ and $31.57 \pm 4.27$ in cases and controls, respectively (table-I). In cases periodontitis was found in 52 patients $(74.3 \%)$ while 37 patients $(52.9 \%)$ were having periodontitis in control group. An association was seen between periodontitis and gestational diabetes mellitus (odds ratio 2.58).

Table-I: Distribution of patients by age.

\begin{tabular}{l|c|c}
\hline Age (Year) & Cases, $\mathbf{n ~ ( \% )}$ & Controls, $\mathbf{n ~ ( \% )}$ \\
\hline $20-35$ & $52(74.3)$ & $56(80)$ \\
\hline $36-45$ & $18(25.7)$ & $14(20)$ \\
\hline Total & $70(100)$ & $70(100)$ \\
\hline Mean \pm SD & $31.37 \pm 5.07$ & $31.57 \pm 4.27$ \\
\hline
\end{tabular}

Table-II: Association between periodontal disease and GDM $(\mathrm{n}=70)$.

\begin{tabular}{|c|c|c|c|c|}
\hline $\begin{array}{l}\text { Period- } \\
\text { ontitis }\end{array}$ & $\begin{array}{c}\text { Cases, } \\
\text { n ( } \%)\end{array}$ & $\begin{array}{c}\text { Control, } \\
\text { n (\%) }\end{array}$ & $\begin{array}{l}\text { Odds } \\
\text { Ratio }\end{array}$ & $95 \%$ CI \\
\hline Yes & $52(74.3)$ & 37 (52.9) & \multirow{2}{*}{2.58} & \multirow{2}{*}{$1.26-5.25$} \\
\hline No & $18(25.7)$ & 33 (47.1) & & \\
\hline
\end{tabular}

Table-III: Stratification with regard to age.

\begin{tabular}{|c|c|c|c|c|c|}
\hline \multirow{2}{*}{$\begin{array}{l}\text { Age } \\
\text { (Year) }\end{array}$} & \multirow{2}{*}{ Group } & \multicolumn{2}{|c|}{ Periodontitis } & \multirow{2}{*}{ Total } & \multirow{2}{*}{$\begin{array}{c}p- \\
\text { value }\end{array}$} \\
\hline & & Yes & No & & \\
\hline \multirow{2}{*}{$20-35$} & Cases & 36 & 16 & 52 & \multirow{3}{*}{0.03} \\
\hline & Controls & 29 & 27 & 56 & \\
\hline \multicolumn{2}{|l|}{ Total } & 65 & 43 & 108 & \\
\hline \multicolumn{2}{|c|}{$\begin{array}{l}\text { Adjusted Odds } \\
\text { ratio }\end{array}$} & \multicolumn{3}{|c|}{3.58 (95\% CI 1.56-3.65) } & \\
\hline \multirow{2}{*}{$36-45$} & Cases & 12 & 6 & 18 & \multirow{3}{*}{0.773} \\
\hline & Controls & 10 & 4 & 14 & \\
\hline \multicolumn{2}{|l|}{ Total } & 22 & 10 & 32 & \\
\hline \multicolumn{2}{|c|}{$\begin{array}{l}\text { Adjusted Odds } \\
\text { ratio }\end{array}$} & \multicolumn{3}{|c|}{0.8 (95\% CI 0.18-3.65) } & \\
\hline
\end{tabular}

Stratification with regard to age was carried out and presented in table-III. The age group 20-35 years showed a statistically significant relationship with GDM and periodontitis (adjusted $\mathrm{OR}=3.5895 \%$ CI 1.56-3.65 $p$-value $=0.03$ ). Whereas, age group 36-45 years did not show any statically significant relationship between GDM and peri- odontitis in this group (adjusted OR=0.8 95\% CI 0.18-3.65 $p$-value=0.773).

\section{DISCUSSION}

Periodontitis is a long lasting debilitating disease caused primarily by bacteria. It causes destruction of tooth supporting structures. Certain studies have linked periodontitis to heart disease $^{13}$, infections of respiratory system, poorly controlled DM, prediabetes, and adverse pregnancy outcomes ${ }^{14}$.

GDM is a type of DM diagnosed in pregnancy. Risk factors like high maternal age, high BMI, and history of previous GDM play an important role ${ }^{15}$. Moreover, presence of a systemic infection leads to insulin resistance and expression of GDM 15 .

Studies 15,16 , established that women with GDM have increased levels of mediators of inflammation in the blood circulation. It is postulated that infection in females during pregnancy is related to development of GDM. Periodontitisis an important source of such bacterial infection and canresult in GDM. Various studies support the relationship between periodontitis and $\mathrm{GDM}^{2}, 16,17$, which is also similar to our findings.

It was established after stratification that young patients have more odds of developing periodontitis after being diagnosed with GDM as compared to old women. This result was consistent with the study of Dasanayake et al ${ }^{18}$, however comparable to Xiong et al16, and Ruiz et al17. It is significant that young maternal age has been shown as asignificant risk factor for the development of periodontitis in patients of gestational diabetes mellitus. In old age periodontitis can be due to multiple other risk factors as lack of brushing, substance abuse, poor oral hygiene and eating habits that is why no statistically significant relationship was established in old age group.

The studies which determined the relationship of oral diseases and DM have various statistical issues as distinct population, small sample size and varied risk factors. Therefore, the results are contradicting. Due to these methodological 
differences it becomes difficult to compare the results. In addition, varied diagnostic criteria for diagnosis of GDM and periodontitis may also have affected the study results.

It has also been established that not only GDM vis-a-vis, poorly controlled DM-2 has been widely associated with greater incidence, extent, and severity of periodontitis ${ }^{19,20}$. In a study by Chavarry et al 21 , it was found that type II DM is a risk factor for development of periodontal diseases and that there is lack of sufficient evidence to confirm whether DM-1 and periodontitis are related. Type I DM develops in young age and this can be the reason for the poor association between dental diseases and type I DM, since periodontitis is more prevalent in old age group.

A better understanding about GDM and periodontitis is important as early intervention in periodontal diseases may prevent the manifestation of type II DM. It is worth mentioning that GDM has grave implications for children and mothers. The paucity of studies regarding the relationship between periodontitis and GDM, as well as their conflicting results, points to the need for multicentric randomized study to fully establish the association. These studies should be conducted in diverse population, must include a large sample size and present new methodological designs.

\section{CONCLUSION}

Periodontitis in pregnancyis found to increase the risk for gestational diabetes mellitus compared to women without periodon-titis.

\section{CONFLICT OF INTEREST}

This study has no conflict of interest to be declared by any author.

\section{REFERENCES}

1. Caton JG, Armitage G, Berglundh T, Chapple IL, Jepsen S. A new classification scheme for periodontal and peri implant diseases and conditions-Introduction and key changes from the 1999 classification. J Periodontol 2018; 89(1): 1-8.

2. Xiong $X$, Elkind Hirsch KE, Vastardis S, Delarosa RL. Periodontal disease is associated with gestational diabetes mellitus: A case control study. J Periodontol 2009; 80(11): 1742-49.

3. Cho N, Shaw JE, Karuranga S, Huang Y, da Rocha Fernandes JD, Ohlrogge AW, et al. IDF Diabetes Atlas: Global estimates of diabetes prevalence for 2017 and projections for 2045. Diabet Resear clinical Pract 2018; 138(1): 271-81.

4. Saini R, Saini S. Periodontal disease: The sixth complication of diabetes. J Family Commun Med 2011; 18(1): 31-35.

5. Esteves Lima RP, Cyrino RM, de Carvalho Dutra B, Oliveira da Silveira J, Martins CC, Miranda Cota LO, et al. Association between periodontitis and gestational diabetes mellitus: Systematic review and meta analysis. J Periodontol 2016; 87(1): 48-57.

6. Abariga SA, Whitcomb BW. Periodontitis and gestational diabetes mellitus: a systematic review and meta-analysis of observational studies. BMC Pregn Child 2016; 16(1): 344-48.

7. da Silva HE, Stefani CM, de Santos Melo N, de Lima AD, Rösing $\mathrm{CK}$, Porporatti AL, et al. Effect of intra-pregnancy nonsurgical periodontal therapy on inflammatory biomarkers and adverse pregnancy outcomes: a systematic review with meta-analysis. Systemat Review 2017; 6(1): 197-00.

8. da Silva Barbirato D, Rodrigues MO, Alves JP, de Castro HP, Fogacci MF. Association between periodontal diseases and adverse gestation outcomes: a review of the current literature. Current Oral Health Reports 2019: 1-3.

9. Komine Aizawa S, Aizawa S, Hayakawa S. Periodontal diseases and adverse pregnancy outcomes. J Obstet Gynaecol Res 2019; 45(1): 5-12.

10. Kumar A, Sharma DS, Verma M, Lamba AK, Gupta MM, Sharma S, et al. Association between periodontal disease and gestational diabetes mellitus-A prospective cohort study. J Clinical Periodontol 2018; 45(8): 920-31.

11. Levin G, Rottenstreich A. Gestational diabetes mellitus and periodontal diseases: a well-known association. Archiv Gynecol Obstet 2018: 298(1): 1-2.

12. Ali MM, Zafar M, Memon RS. Gestational diabetes mellitus and periodontal diseases: a newly well-established association. Archives of gynecology and obstetrics. 2018; 298(2): 443-44.

13. Komine Aizawa S, Aizawa S. Periodontal diseases and adverse pregnancy outcomes. J Obstet Gynaecol Res 2019; 45(1): 5-12.

14. Dunn AB, Hanson L, VandeVusse L, Leslie S. Through the Microbial Looking Glass: Premature Labor, Preeclampsia, and Gestational Diabetes: A Scoping Review. J Perinat Neonatal Nurs 2019; 33(1): 35-51.

15. Mittas E, Erevnidou K, Koumantakis E, Papavasileiou S, Helidonis E. Gingival condition of women with gestational diabetes on a Greek island. Special Care Dent 2006; 26(5): 214-19.

16. Xiong X, Buekens P, Fraser WD, Beck J. Periodontal disease and adverse pregnancy outcomes: a systematic review. BJOG: An Int J Obstet Gynaecol 2006; 113(2): 135-43.

17. Ruiz DR. Periodontal disease in gestational and type 1 diabetes mellitus pregnant women. Oral Dis 2011; 17(1): 515-21.

18. Dasanayake AP, Chhun N, Tanner AC, Craig RG, Lee MJ, Moore AF, et al. Periodontal pathogens and gestational diabetes mellitus. J Dental Res 2008; 87(4): 328-33.

19. Victor DJ, Subramanian S, Gnana PP, Joseph BJ. Tumor necrosis factor-alpha-308 gene polymorphism in the association between gestational diabetes mellitus and chronic periodontitis in South Indian population. J Pharmacol Pharmacother 2018; 9(2): 109-12.

20. Sanz M, Ceriello A, Buysschaert M, Chapple I, Demmer RT. Scientific evidence on the links between periodontal diseases and diabetes: Consensus report and guidelines of the joint workshop on periodontal diseases and diabetes by the International Diabetes Federation and the European Federation of Periodontology. J Clinical Periodontol 2018; 45(2): 138-49.

21. Chavarry NG, Vettore MV, Sansone C. The relationship between diabetes mellitus and destructive periodontal disease: A metaanalysis. Oral Health Prev Dent 2009; 7(2): 107-27. 